Available online at GSC Online Press Directory

GSC Biological and Pharmaceutical Sciences

e-ISSN: 2581-3250, CODEN (USA): GBPSC2

Journal homepage: https://www.gsconlinepress.com/journals/gscbps

(RESEARCH ARTICLE)

\title{
Natural product (Abutilon hirtum extracts) in treating environment - related infections (Salmonellosis and Typhoid fever)
}

\author{
Dawang Noel DeNaan*
}

School of Science and Technology, Plateau State Polytechnic, Barkin Ladi, P.M.B 02023, Bukuru, Nigeria.

Publication history: Received on 30 August 2020; revised on 06 November 2020; accepted on 10 November 2020

Article DOI: https://doi.org/10.30574/gscbps.2020.13.2.0282

\begin{abstract}
Salmonella is considered a serious public health burden especially in areas of low economic status and high temperature. The continuous emergence of some Salmonella species to even third generation antibiotics is a threat to health care delivery. Thus, this study aimed at screening multidrug resistant (MDR) Salmonella isolates and subjecting them to Abutilon hirtum extract and fraction as a means of possible discovery of new antimicrobial of plant nature in treatment of environment related infections. Ten serotyped clinical Salmonella isolates were obtained from Jos University Teaching Hospital (JUTH), Nigeria. The plant fractions were obtained by open column chromatography. Phytochemical screening was done using Standard Qualitative method. The bioassay of the crude and fraction extracts (AF9) against MDR Salmonella isolates was by Well Agar diffusion and broth micro dilution method respectively. All Salmonella isolates exhibited resistance against more than 3 antimicrobials (MDR). However, all the isolates (100\%) were susceptible to ciprofloxacin and $60 \%$ sensitive to ceftriaxone but showed $100 \%$ resistance against amoxicillin, erythromycin, tetracycline and amoxicillin +clavulanic acid. The A.hirtum extract showed the presence of alkaloids, flavonoides, tannins, saponins, cardial glycosides, terpenes and steroids, phenol and resins. $80 \%$ of the isolates were susceptible to the crude extract at concentration of $200 \mathrm{mg} / \mathrm{ml}$ but susceptibility decreased as concentration decreased. The MIC and MBC of the plant fraction (AF9) against the isolates ranged from $150 \mu \mathrm{g} / \mathrm{ml}-300 \mu \mathrm{g} / \mathrm{ml}$ and $300 \mu \mathrm{g} / \mathrm{ml}-$ $600 \mu \mathrm{g} / \mathrm{ml}$ respectively. This plant may probably be a new antimicrobial for treating MDR Salmonella infections.
\end{abstract}

Keywords: Multidrug Resistant Salmonellae; Abutilon hirtum extracts; bioactive molecules; environment; Nigeria

\section{Introduction}

Antibacterial agents are the most useful substances in combating the menace of infectious diseases caused by pathogenic microorganisms worldwide [1].The burden of the infections is becoming more threatening as a result of emergence of multidrug resistant microorganisms.

Report has shown consistently that gastrointestinal infections with bacterial pathogens are positively correlated with ambient temperature. Again, Ahmad and Akil [2] have documented that socioeconomic status and climate change are said to contribute to the increased rates of Salmonella. The genus Salmonella has been responsible for both salmonellosis and typhoid fever. SalmonellaTyphi also causes an asymptomatic and persistent (chronic) infection. These infected persons are typhoid fever carriers and are capable of shedding bacteria and sustaining transmission within the community $[3,4]$.

The Abutilon hirtum is a wild plant growing on rocks and is indigenous to Berom natives of Plateau State, Nigeria. Its leaves are used for cooking soup and have been consumed over the years without any side effect on the users and it is

${ }^{*}$ Corresponding author: Dawang Noel DeNaan

School of Science and Technology, Plateau State Polytechnic, Barkin Ladi, P.M.B 02023, Bukuru, Nigeria.

Copyright (C) 2020 Author(s) retain the copyright of this article. This article is published under the terms of the Creative Commons Attribution Liscense 4.0. 
claimed to be effective in treatment of typhoid fever. Thus, this study aimed at screening multidrug resistant (MDR) Salmonella isolates and subjecting them to Abutilon hirtum extract and fraction as a means of possible discovery of new antimicrobial of plant nature in treatment of environment related infection.

Salmonella which is the causative agent of typhoid fever and salmonellosis has feature to form biofilms in abiotic surfaces outside the host, such as in farms, food processing industry, kitchen or toilets, in plant surfaces, or even in animal epithelial cells, therefore, contributing to its resistance and persistence[5].There was an estimated disease burden of 20.6 million cases in low- and middle-income countries in 2010, presenting typhoid fever to remain an enteric disease of public health concern[6, 7].However, marked improvement in water, sanitation and sewage removal have greatly reduced typhoid fever incidence only in most industrialized countries [3, 8, 9, 10]. Salmonella enteric serovarTyphi that causes typhoid fever is specific to human and the non-typhoidal Salmonella spp are transmitted by the fecal -oral route between humans, through the ingestion of contaminated food and water.

An epidemic of invasive non-typhoidal Salmonella (iNTS) infections had occurred in sub-Saharan Africa and genomic analysis and clinical observation revealed these organisms are evolving to become more typhoid like in regard to patterns of transmission and virulence. It is worrisome that a prototypical African NTS strain has lost traits required for environmental stress resistance, consistent with an adaptation to a human-model of transmission [11].

Over time Salmonella species have demonstrated resistance to many antibiotics as a result of mutation, horizontal and vertical gene transfer. These factors are promoted by miss-used of antibiotics, use of antibiotics as growth promoters in agriculture, poverty, over crowdedness, lack of portable water, poor hygiene practices of handling, raw animal product and food in general and biofilm barriers. Particularly improper cooking methods by food handlers in restaurants and canteens could be responsible for spread of multidrug resistant Salmonella since most of developing countries populations live below the average level of $\$ 1$ per day meal, hence, they made up their minds to patronizing restaurants and canteens of questionable cooking standards [12,13]. Also flooding and dumping of untreated waste /sewage have been reported to contribute to the transmission of these agents $[14,15]$.

Right from the time memorial, man had learned to use plants around his environment by trial and error for treatment of ailments. This is in line with what is documented in Ezekiel 47:12 that plants are for healing and food. Today, use of plants is the basis of sophisticated traditional medicine system that has existed for thousands of years and has continued as new remedies for man and animal [16] .Majority of the rurals in developing countries like Nigeria largely depend on traditional use of medicinal plants handed over to them from generation to generation. Traditional medicines have continued to be more relevant due to some features that are unique to this medicine in terms of efficacy and safety [17].Medicinal plants are sources of novel chemical entities that have beneficial pharmacological and therapeutics potentials. They can either be administered directly or their extracts used as starting material in formulation of conventional drugs [18].

\section{Material andmethods}

\subsection{Bacterial isolates}

Ten clinical Salmonella isolates serotyped by polyvalent antiserum Poly 0, 1-67 and Poly H-1+2(SIFINGERMANY) Subgroup and Monavalent sera (Carper Laboratories, London) were collected from Medical Micro biology Department of the University of Jos Teaching Hospital.

\subsection{Antibiogram}

Kirby-Bauer's method was adopted using ceftriaxone, cotrimoxazole, ciprofloxacin, erythromycin, chloramphenicol, tetracycline, gentamicin, cloxacillin, amoxicillin and amoxicillin + clavulanic acid to obtain the antibiogram against the isolates.

\subsection{Collection and preparation of the plant sample}

Abutilon hirtum was collected from BarkinLadi L.G.A of Plateau State, Nigeria and identified by a plant taxonomist; Late Dr.FidelisTiseer of A.B.U Zaria. The procedure of Ndip et al. [19] was used for the extraction of the plant material with slight modification by using thermostatic water Cabinet (model HH-W420, XMTD-204 and TT42D Multipurpose use. Techmel and Techmel, USA) at 1000C instead of rotor vapor to concentrate the plant extracts. Analytical grade $86 \%$ methanol was used for the cold extraction. 


\subsection{Column chromatography}

The extract of A.hirtum was fractionated by column chromatography process as reported by Dawang et al. [20] using the following mobile phase; n-hexane: Methanol(MeOH) as $(10: 0,15: 1,9: 4,8: 2,7: 3,6: 4,5: 5,4: 6,3: 7,2: 8)$ and MeOH:Ethanol (EtoAC) $(10: 0,9: 1,8: 2,7: 3,6: 4,5: 5)$ and the effluent was collected in a small fraction $(150 \mathrm{~cm} 3)$ in a beaker. Fractions from crude plant extract were pooled together based on similar profile on Thin Layer Chromatography (TLC, AlugramXtra SIL G/uv 254, MAC HERY-NAGEL GmbH and Co. Kg, Germany) to yield 11 A.hirtum leaf fractions of AF1AF11 due to variance in polarity and types of constituents extracted [21].However only 1 most effective fraction obtained after preliminary bioassay of the 11 fractions was tested against the isolates.

\subsection{Phytochemical screening}

The phytochemical screening of ethyl acetate extract of A.hirtum extract was carried out using standard qualitative procedure [22, 23].

\subsection{Sensitivity test of the crude extract}

Agar Well Diffusion Method was used to determine the sensitivity of the isolates to the plant crude extract. A MuellerHintor agar plate was inoculated with $0.7 \mathrm{ml}$ of suspended isolate of inoculum size equivalent to $1 \mathrm{X} 108 \mathrm{cfu} / \mathrm{ml}$ and the excess fluid at the edge of the petri dish was removed with sterile cotton wool to obtain confluent growth. The plates were then kept for few minutes to dry. Wells of $6 \mathrm{ml}$ in diameter were aseptically punched with a sterile cork borer. A stock concentration of the crude plant extract was obtained by dissolving $2 \mathrm{~g}$ of crude plant extract in $10 \mathrm{ml}$ of DMSO and $100 \mathrm{mg} / \mathrm{ml}$ of the crude extract was prepared. Two wells punched in a plate were filled with $200 \mathrm{mg} / \mathrm{ml} \mathrm{and} 100 \mathrm{mg} / \mathrm{ml}$ of separately and one well in the same plate was separately filled with DMSO (negative control). The plates were left again for some time for the extracts to diffuse into the agar, after which they were incubated at 370C for over 18 hours. The zone of inhibition was measured to the nearest millimeter and mean zone of inhibition was calculated for each extract concentration [24].

\subsection{Determination of minimum inhibition concentration (MIC) of fraction of A.hirtum}

The MIC of the leaf fraction (Methanolic AF9) against the various isolates was done by using the 96-well micro dilution method described by Nvau et al.[25] (2011), but with slight modification of using 8 wells instead of 12 wells. After about 24 hours sub-culturing of the isolates on nutrient agar and Xylose Lysine Deoxycholate (XLD), 4-5 colonies of the same appearance of each isolate was emulsified in sterile normal saline according to Ndip et al. [19] documented by Nyenje and Ndip [26] and adjusted to $0.5 \mathrm{McF}$ arland Scale $(1 \times 108 \mathrm{cfu} / \mathrm{ml})$. Fifty microlitres $(50 \mu \mathrm{l})$ of Brain Heart Infusion (BHI) broth was introduced into wells 2 to 8 . One hundred microlitre of $0.006 \mathrm{~g}$ of the extract dissolved in $10 \mathrm{ml}$ of DMSO was

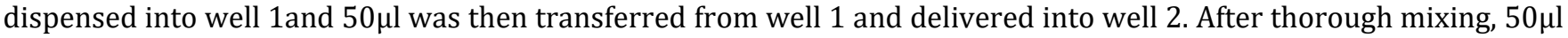
was again transferred from well 2 to 3 and the same procedure was repeated through to well 8 and from well $8,50 \mu l$ was discarded. Thereafter, $50 \mu \mathrm{l}$ of inoculum was introduced to all the wells. The wells were then covered with plastic tape, incubated for about 24 hours and observed for turbidity. The well before the one that showed turbidity (growth) was noted as Minimum Inhibitory Concentration (MIC).

\subsection{Determination of the minimum bactericidal concentration (MBC) of fraction of A.hirtum}

A sterile wire loop was dipped into the wells of minimum inhibitory concentration that showed no turbidity (no bacterial growth) and streaked on nutrient agar and incubated overnight. The MBC was obtained as the lowest concentration preventing the growth of bacteria [21].

\section{Results and discussion}

The clinical salmonellae isolates showed varied multidrug resistant (MDR) patterns with AmoxEryTetCxcCotChlAuGen appearing the most (Table 1). The methanolic leaf extract of Abutilon hirtum showed the presence of alkaloids, flavonoids, saponins, cardiac glycoside, sterpenes and steroids, phenols and resins whereas balsam was absent (Table 2). Table 3 showed that at concentration of $200 \mathrm{mg} / \mathrm{ml}, 80 \%$ of the isolates were susceptible to the extract. The AF9Methanolic fraction showed MIC ranging from $150 \mu \mathrm{g} / \mathrm{ml}$ to $300 \mu \mathrm{g} / \mathrm{ml}$ while MBC varied from $300 \mu \mathrm{g} / \mathrm{ml}$ to $600 \mu \mathrm{g} / \mathrm{ml}$ against the clinical Salmonella isolates (Table 4). Figure 1 showed percentage susceptible and resistant of the isolates to the various antimicrobials used with $100 \%$ resistant to amoxicillin, erythromycin, tetracycline, cloxocillin and amoxicillin + cluvalanic acid but $100 \%$ and $60 \%$ susceptible to ciprofloxacin and ceftrixone respectively. 
Table 1Distribution of Susceptibility/ Resistance to Antimicrobials among Salmonella Isolates from Patients of University of Jos teaching hospital, Jos, Nigeria.

\begin{tabular}{|c|c|c|c|c|c|c|c|c|c|c|c|}
\hline \multicolumn{2}{|c|}{$\begin{array}{l}\text { Isolate } \\
\text { id/antimicro } \\
\text { bials }\end{array}$} & & & & & & & & & & \\
\hline No & $\mathrm{Tx}$ & $\mathrm{Cl}$ & Amox & Ery & Tet & $\mathrm{Cxc}$ & Cot & Chl & $\mathrm{Au}$ & Gen & MDR Pattern \\
\hline 1 & $\mathrm{~S}$ & $\mathrm{~S}$ & $\mathrm{R}$ & $\mathrm{R}$ & $\mathrm{R}$ & $\mathrm{R}$ & $\mathrm{R}$ & $\mathrm{S}$ & $\mathrm{R}$ & $\mathrm{R}$ & AmoxEryTetCxcCotAuGen. \\
\hline 2 & $S$ & $\mathrm{~S}$ & $\mathrm{R}$ & $\mathrm{R}$ & $\mathrm{R}$ & $\mathrm{R}$ & $\mathrm{R}$ & $\mathrm{R}$ & $\mathrm{R}$ & $\mathrm{S}$ & AmoxEryTetCxcCotChlAu \\
\hline 3 & $\mathrm{R}$ & $S$ & $\mathrm{R}$ & $\mathrm{R}$ & $\mathrm{R}$ & $\mathrm{R}$ & $\mathrm{R}$ & $S$ & $\mathrm{R}$ & $\mathrm{S}$ & TxAmoxEryTetCxcCotAu \\
\hline 4 & $\mathrm{R}$ & $S$ & $\mathrm{R}$ & $\mathrm{R}$ & $\mathrm{R}$ & $\mathrm{R}$ & $\mathrm{R}$ & $S$ & $\mathrm{R}$ & $\mathrm{R}$ & TxAmoxEryTetCXcCotAuGen \\
\hline 5 & $S$ & $S$ & $\mathrm{R}$ & $\mathrm{R}$ & $\mathrm{R}$ & $\mathrm{R}$ & $\mathrm{S}$ & $\mathrm{R}$ & $\mathrm{R}$ & $\mathrm{S}$ & AmoxEryTetCxcChlAu \\
\hline 6 & $\mathrm{R}$ & $S$ & $\mathrm{R}$ & $\mathrm{R}$ & $\mathrm{R}$ & $\mathrm{R}$ & $\mathrm{R}$ & $\mathrm{R}$ & $\mathrm{R}$ & & TxAmoxEryTetCxcCotChlAuGen \\
\hline 7 & $S$ & $S$ & $\mathrm{R}$ & $\mathrm{R}$ & $\mathrm{R}$ & $\mathrm{R}$ & $\mathrm{R}$ & $\mathrm{R}$ & $\mathrm{R}$ & $\mathrm{R}$ & AmoxEryTetCxcCotChlAuGen \\
\hline 8 & $\mathrm{R}$ & $\mathrm{S}$ & $\mathrm{R}$ & $\mathrm{R}$ & $\mathrm{R}$ & $\mathrm{R}$ & $\mathrm{R}$ & $\mathrm{S}$ & $\mathrm{R}$ & $\mathrm{R}$ & TxAmoxEryTetCxcCotAuGen \\
\hline 9 & $S$ & $S$ & $\mathrm{R}$ & $\mathrm{R}$ & $\mathrm{R}$ & $\mathrm{R}$ & $\mathrm{R}$ & $\mathrm{R}$ & $\mathrm{R}$ & & AmoxEryTetCxcCotChlAuGen \\
\hline 10 & S & S & $\mathrm{R}$ & $\mathrm{R}$ & $\mathrm{R}$ & $\mathrm{R}$ & $\mathrm{R}$ & $S$ & $\mathrm{R}$ & & AmoxEryTetCxcCotAu \\
\hline
\end{tabular}

Tx (Ceftriaxone), Cl(Ciprofloxacin), Amox(Amoxicillin), Ery (Erythromycin) Tet (Tetracycline), Cxc (Cloxocillin), Cot (Cortimoxazole), Chl (Chloramphenicol), Au (Amoxicilin + Clavalanic acid), Gen (Gentamicin), S(Susceptible) $\mathrm{R}($ Resistiant).

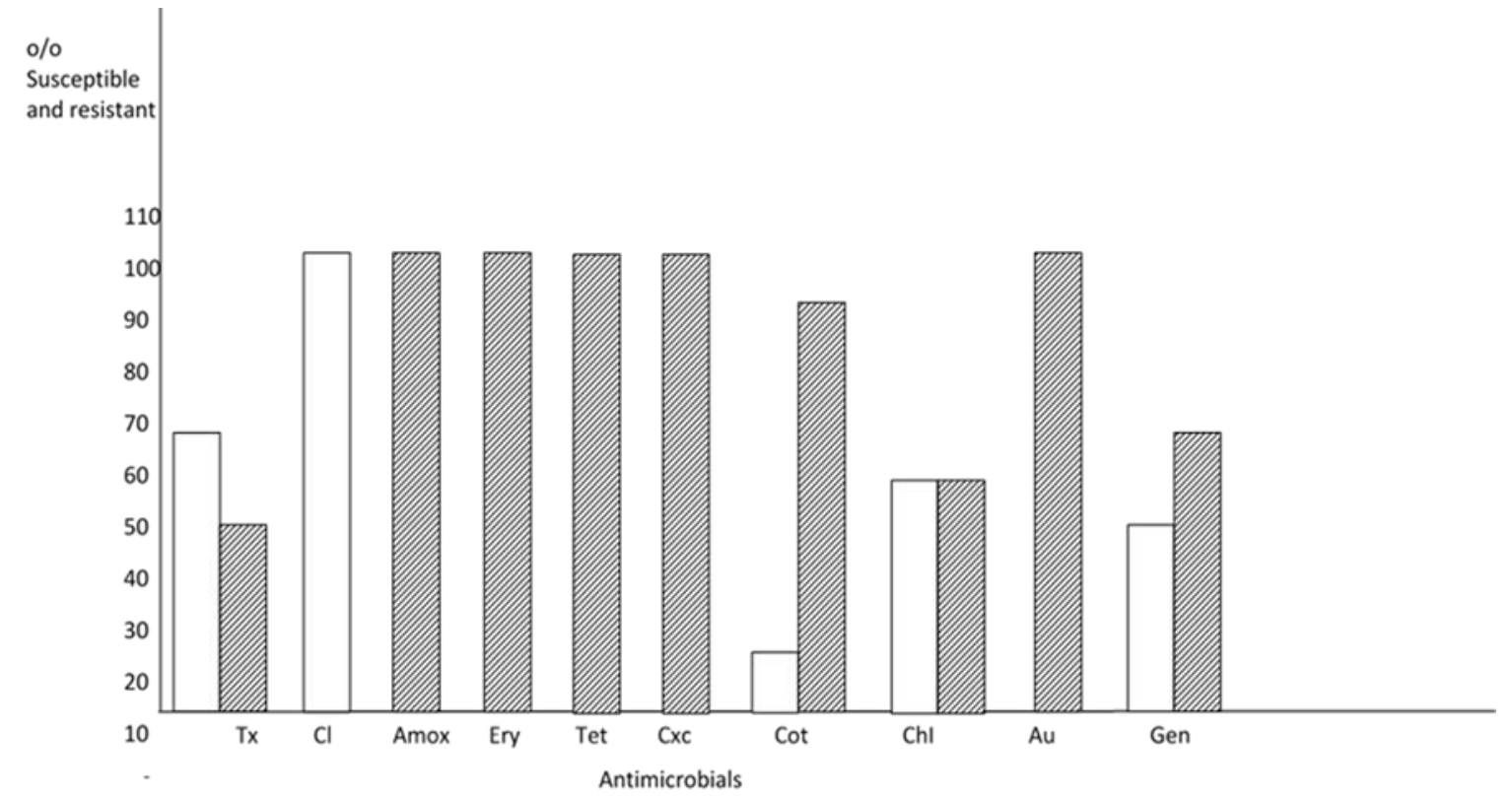

Figure 1.Susceptibility and Resistance of Salmonella isolates to Antimicrobials

Tx (Ceftriaxone), Cl(Ciprofloxacin), Amox(Amoxicillin), Ery (Erythromycin) Tet (Tetracycline), Cxc (Cloxocillin), Cot (Cortimoxazole), Chl (Chloramphenicol), Au (Amoxicilin + Clavalanic acid), Gen (Gentamicin), ( Susceptible)

(Resistiant). 
Table 2. Phytochemical constituents of methanolic leaf extract of Abutilon hirtum.

\begin{tabular}{|l|l|}
\hline Chemical Components & Abutilon hirtum \\
\hline Alkaloids & + \\
\hline Flavonoids & + \\
\hline Tannins & + \\
\hline Saponins & + \\
\hline Cardiac glycosides & + \\
\hline Terpenes \& steroids & + \\
\hline Balsam & - \\
\hline Phenols & + \\
\hline Resins + (positive/present) , - (Negative/Absent)
\end{tabular}

Table 3.Efficacy of Abutilon hirtum methanolic crude leaf extract against clinical Salmonella isolates.

\begin{tabular}{|l|l|l|l|}
\hline Isolate i.d no & Serogroup & $\mathbf{2 0 0} \mathbf{m g} / \mathbf{m l}$ & $\mathbf{1 0 0 m g} / \mathbf{m l}$ \\
\hline 1 & B & S & R \\
\hline 2 & C & S & R \\
\hline 3 & C & S & S \\
\hline 4 & A & S & S \\
\hline 5 & C & R & R \\
\hline 6 & C & S & R \\
\hline 7 & D & S & R \\
\hline 8 & C & R & R \\
\hline 9 & C & S & R \\
\hline 10 & B & S & S \\
\hline
\end{tabular}

i.d no. (Identification Number), Zone to inhibition <14mm (resistant), $>14 \mathrm{~mm}$ (susceptible).

Table 4.MIC and MBC of AF9 methanolic Abutilon hirtum fraction against the clinical Salmonella isolates.

\begin{tabular}{|l|l|l|}
\hline Isolate i.d no & MIC $(\boldsymbol{\mu g} / \mathbf{m l})$ & MBC $(\boldsymbol{\mu g} / \mathbf{m l})$ \\
\hline 1 & 300 & 600 \\
\hline 2 & 150 & 600 \\
\hline 3 & 150 & 600 \\
\hline 4 & 300 & 600 \\
\hline 5 & 300 & $>600$ \\
\hline 6 & 300 & 600 \\
\hline 7 & 300 & 300 \\
\hline 8 & 300 & 300 \\
\hline 9 & 300 & 300 \\
\hline 10 & 300 & 600 \\
\hline
\end{tabular}

i.d No (identification number), MIC (minimum inhibition concentration, MBC (Minimum bactericidal concentration, AF9 (Abutilon fraction 9).

The salmonellae multidrug resistant patterns observed in this study are in conformity to several reports indicating varied antibiotic profiles of salmonellae in sub-Saharan African countries. This could due to the fact that infectious diseases are much more serious in the tropical regions such as Southeast Asian, South Asian, and Africa (Nigeria, where 
this recent research was carried out) because the warm and humid environment favour the growth and propagation of microorganisms [27].The swapping between plasmid(s) and the bacterial chromosome and integration of resistance genes into genetic elements like integrons probably contributed in acquisition and dissemination of resistance genes partly as a result of environmental factors[28]. Marks et al. [29] have reported ciprofloxacin resistant S. paratyphi A and iNTS in Senegal and Ghana respectively although it is not similar to this finding which could be as a result of geographical location. Also, reported was iNTS isolate from Kenya found to be resistant to ceftriaxone as the case in this present study.

The presence of bioactive compounds in A. hirtum confirms its antisalmonellae potentials. This is in line with the World organization [30] which reported that medicinal plants would be the best source to obtain a variety of drugs. At $200 \mathrm{mg} / \mathrm{ml}$ of $A$. hirtum methanolic leaf extract, all the salmonellae isolates were susceptible unlike at $100 \mathrm{mg} / \mathrm{ml}$. This shows that as the concentration of the extract increased, its potency also increased. Thus, effective treatment of this multidrug resistant menace entails the development of new pharmaceuticals or some potential source of novel drugs. Some commonly used medicinal plants in our environment might be an excellent source of drugs to fight off this problem [31].

The effectiveness of the antibacterial activity of $A$. hirum was demonstrated by low MIC of $150 \mu \mathrm{g} / \mathrm{ml}$ to $300 \mu \mathrm{g} / \mathrm{ml}$ against the tested Salmonellae. At $300 \mu \mathrm{g} / \mathrm{ml}$ to $600 \mu \mathrm{g} / \mathrm{ml}$ range of the MBC, the plant showed bactericidal effect against all the organisms except one. This finding is similar to that of Dawang et al. [20] who reported sub fraction, AF9, and AF2 of $A$. hirtum to exhibiting antisalmonellae potency at $75 \mu \mathrm{g} / \mathrm{ml}$ and $150 \mu \mathrm{g} / \mathrm{ml}$ respectively. The medicinal properties of the plant extract are due to the synergetic effects of the bioactive substances present. Some researchers have suggested that the main active molecules in plants that are responsible for antidiarrhoeal activity are tannins and tannic acid, flavonoids, alkaloids, sesquiterpenes, terpenes and terpenoids [32].

There are several confirmations on the effectiveness of plants extracts on salmonellae. For instance, Urtic aurens aqueous extract was demonstrated to have a significant effect on mice mortality when administrated in S. Typhimurium infected rats at considerably low dosages ( $3 \mathrm{mg} / \mathrm{kg}$ ) [33]. Also, Terminalia belerica fruits aqueous extract administered to mice infected with lethal doses of S. Typhimurium showed a dose dependent effect, with 83.3 of the mice surviving after 15 days, while all of the controls have died within seven days [34].Additionally, Kengni et al. [35] experimented that the faeces of infected rats treated with Harungana madagascariensis aqueous leaf extract $(25 \mathrm{mg} / \mathrm{kg}) \mathrm{were}$ free $o f$ Salmonella after 16 days in both male and female animals, even at low extract dose concentrations.

\section{Conclusion}

In conclusion, tropical countries are more prone to microbial infections due to the conducive environment where the causative agents can easily thrive beside the socioeconomic statue of the developing countries. Abutilon hirtum as one of the wild plants found within the environment with further processing could be used in treating microbial infections beside sustained clean environment.

\section{Compliance with ethical standards}

\section{Acknowledgments}

I would like to acknowledge the contribution of Dr. Solomon Opajobi for the initial screening of the Salmonella isolates and the Management of Plateau State Polytechnic, B/Ladi for providing the research environment for this work.

\section{Disclosure of conflict of interest}

I sincerely declare that there is no conflict of interest in the course of this work.

\section{References}

[1] Bhatia R, Narain JP.The growing challenge of antimicrobial resistance in the South-East Asia Region - are we losing the battle? Indian Journal of Medical Research. 2010; 132(5): 482-486.

[2] Ahmad HA, Akil.Effects of Environment and Socioeconomics on Salmonella Infections. 2017.

[3] Parry CM, Hien TT, Dougan G, White NJ, Farrar JJ. Typhoid fever.N Engl J Med. 2002;347:1770-82. 
[4] Gonzalez-Escobedo G, Marshall JM, Gunn JS. Chronic and acute infection of the gall bladder by Salmonella Typhi: understanding the carrier state. Nat Rev Microbiol. 2011; 9:9-14.

[5] Steenackers H, Hermans K,Vanderleyden J, De Keersmaecker SCJ. Salmonella biofilms: An overview on occurrence, structure, regulation and eradication. Food Res. Int.2011; 45: 502-531.

[6] Mogasale V, Maskery B, Ochiai RL, Lee JS, Mogasale VV, Ramani E,Kim YE, Park JK, Wierzba TF. Burden of typhoid fever in low-income and middle-income countries: a systematic, literature-based update with risk-factor adjustment. Lancet Glob Health.

[7] Mogasale V, Mogasale VV, Ramani E, Lee JS, Park JY, Lee KS,Wierzba TF. Revisiting typhoid fever surveillance in low and middle income countries: lessons from systematic literature review of population-based longitudinal studies. BMC Infect Dis.2016; 16:35.

[8] Crump JA, Luby SP,Mintz ED. The global burden of typhoid fever. Bull World Health Organ. 2004; 82:346-53.

[9] Crump JA,Mintz ED. Global trends in typhoid and paratyphoid Fever.Clin Infect Dis. 2010;50:241-6.

[10] Lee JS, Mogasale VV, Mogasale V,Lee K. Geographical distribution of typhoid risk factors in low and middle income countries.BMC Infect Dis.2016;16:732.

[11] Singletary LA, Karlinsey JE, Libby SJ, Mooney JP, Lokken KL, Tsolis RM, Byndloss MX, Hirao LA, Gaulke CA, Crawford RW, Dandekar S, Kingsley RA, Msefula CL, Heyderman RS,Fang FC. Loss of multicellular behavior in epidemic African nontyphoidal Salmonella entericaserovar Typhimurium ST313 strain D23580. mBio. 2016; $7(2)$.

[12] Akinyemi KO, Fashola M.O, Habib N, Akinwande E. Vended foods in Lagos, Nigeria: a potential reservoir for the spread of emerging strains of drug resistant bacteria. Health. 2013; 5(4): 675-680.

[13] David OM, Oluyege A0.Antibiotic resistance and plasmid carriage among Salmonella Typhi isolated from food handlers in a Nigeria University. Int. J. Curr. Microbiol. Appl. Sci. 2015; 4(3): 906-914.

[14] Fiji Ministry of Health. Meeting report. Expert consultation on typhoid fever vaccination in Fiji. Suva (Fiji): Fiji Ministry of Health.2010.

[15] Greenwell J, McCool J, Kool J, Salusalu M. Typhoid fever: hurdles to adequate hand washing for disease prevention among the population of a peri-urban informal settlement in Fiji.Western Pac Surveill Response J.2013; 4:41-5.

[16] Johnsy G, Beena S,aviyarasan V. Ethnobotanicalsurveyofmedicinal plants used for the treatment of diarrhoea and dysentery.Int.J.Med.Med.Sci. 2013; 3(1): 332-338.

[17] Nanjan MJ. Quality control and standardization of traditional medicine/ herbal drugs. In: Proceedings of an International Conference on Challenging and Emerging Dimensions in Medicinal/Herbal Plants and their Products: A Global Perspective,ChennaiTrade Centre, Chennai, India. 2010.

[18] Khan I, Jan SA, Shinwari ZK, Ali M, Khan Y,Kumar T. Ethnobotany and medicinal uses of folklore medicinal plants belonging to family acanthaceae: An updated review. MOJ Biol Med. 2017; 1(2):34-38.

[19] Ndip RN, Malange AE, Mbullah SM, Luma HN, Malongue A, Ndip LM, Wirmum C, Efange SMN.Invitro antiHelicobacter pyloric activity of extracts of selected medicinal plants from North West Cameroon.Journal of Ethnopharmacology. 2007; 114(3):432-457.

[20] Dawang DN, Festus O, Patricia L. Search for Cheaper Treatment of Typhoidal and Non Typhoidal Salmonella Infections from Abutilon hirtum (Florida keys) Crude Extract and Fractions. The Journal of Ethnobiology and Traditional Medicine. Photon. 2016; 126: 1176-1184.

[21] ourouge AS, Nazlina I, Wan AY. Bio-guided study on Melastoma malabathricum Linn leaves and elucidation of its biological activities.American Journal of Applied Sciences. 2007; 10(8):767-778.

[22] Trease GE, Evans WC. A textbook of Pharmacognosy, 13th edition.Bailere-Tridall, London. $1989 ; 315-544$.

[23] Sofowora EA.Medicinal Plants and Traditional Medicine in Africa.2 edn, England, John and Wiley and Sons Ltd. 1993; 55-62.

[24] Boyanova L, Gergova G, Nikolor R, Derejian S, Lazarora E, Katsarov N, Mitov I, Kraster Z. Activity of Bulgarian propolis against 94 Helicobacter pyloric strains in vitro by agar-well diffusion agar dilusion and disc diffusion methods.Journal Medical microbiology. 2005; 54:481-483. 
[25] Nvau JB, Oladosu PO, Orishadipe AT. Antimycobacterial evaluation of some medicinal plants used in Plateau State of Nigeria for the treatment of tuberculosis.Agriculture and Biology Journal of North America. 2011; 1270-1272.

[26] Nyenje M, Ndip RN. In-vitro antimicrobial activity of crude acetone extract of the stem bark of Combretummolle against selected bacterial pathogens.Journal of medical plants Research. 2011; 5(21): 5315-5320.

[27] Eldeen IMS, Elgorashi EE,Van Staden J. Antibacterial, anti-inflammatory, anti-cholinesterase and mutagenic effects of extracts obtained from some trees used in South African traditional medicine .Journal of Ethnopharmacology. 2005; 102 (3): 457-464.

[28] Rodicio MR , Herrero A, Rodriguez I, Garcia P, Montero I, Beutlich J, Rodicio R, Guerra B ,Mendoza MC. Acquisition of antimicrobial resistance determinants of virulence plasmids by specific serotypes of Salmonella enteric nontyphoid. Review Medical Microbiology. 2011;22:55-65.

[29] Marks F, von Kalckreuth V, Aaby P, Adu-Sarkodie Y, El Tayeb MA, Ali M et al. Incidence of invasive salmonella disease in sub-Saharan Africa: a multicentre population-based surveillance study. Lancet Glob Health. 2017;5(3).

[30] World Health Organization. World Health Organization, WHO Traditional Medicine Strategy, Geneva. 2002.

[31] Sarita M, Shisir L, Raj KD. In Vitro Antimicrobial Activity of Some Medicinal Plants against Human Pathogenic Bacteria .Journal of Tropical Medicine. 2019; Article ID 1895340, 5 pages.

[32] Gairola S, Sharma J, Gaur RD, Siddiqi TO Painuli RM. Plants used for treatment of dysentery and diarrhea by the Bhoxa community of district Dehradun, Uttarakhand, India.Journal of Ethnopharmacology. 2013; 150: 990-1007.

[33] Barkaoui T,Kacem R, Guesmi F,Blell A, Landoulsi A. Article evaluation of antibacterial and antioxidant properties of Urticaurens extract tested by experimental animals.Int. J. Pharmacol. 2017; 13: 332-339.

[34] Madani A, Jain SK. Anti-salmonella activity of Terminalia belerica.In vitro and in vivo studies. Indian J. Exp. Biol. 46: 817-821.

[35] Kengni F,Fodouop SPC, Tala DS, Djimeli MN, Fokunang C, Gatsing D. Antityphoid properties and toxicity evaluation of Harunganamadagascariensis Lam (Hypericaceae) aqueous leaf extract. J. Ethnopharmacol. 2016; 179: $137-14$. 